\title{
Identifying gaps in after-hours endoscopic practices
}

\author{
Catherine Dubé MD MSc FRCPC, Robert J Hilsden MD PhD FRCPC
}

$\mathrm{I}_{\mathrm{c}}^{\mathrm{n}}$ $\mathrm{n}$ the present issue of the Canadian Journal of Gastroenterology, the Canadian Association of Gastroenterology (CAG)'s Clinical Affairs Committee presents the results of a survey regarding after-hours endoscopy staffing and practices, highlighting some significant and likely clinically relevant gaps (pages 871-876) (1). Essentially, there is a significant variation across Canadian provinces in access to specialized endoscopy staff, which was associated with variations in gastroenterologists' satisfaction and raises concerns about the safety of after-hours endoscopic procedures in some Canadian centres.

Muthiah et al (1) conducted a survey among clinical members of the CAG regarding their after-hours endoscopy practices. Survey questions addressed the type and intensity of nursing assistance, the access to other services and locations, such as emergency rooms and intensive care units, the physical location of procedures, the person in charge of decontamination and the frequency of after-hours procedures. Results were analyzed according to practice type (academic versus community based; adult versus pediatric care) and province. The survey results highlighted two key geographical variations.

First, access to endoscopy nurses for after-hours, emergent procedures is not universal, which is in contrast to daytime procedures, which are typically performed in the presence of at least one endoscopy nurse (2). Notably, only $50 \%$ of British Columbia and $51 \%$ of Ontario respondents could access an on-call trained endoscopy nurse, while this was the case in more than $90 \%$ of respondents from the rest of the country. Alberta respondents, who reported a high level of satisfaction with their after-hours practices, could access an on-call trained endoscopy nurse $96 \%$ of the time. By definition, after-hours cases are more likely to require therapeutic interventions, to be more challenging and involve a greater risk of complications. Such cases, therefore, require optimal assistance, which includes the presence of a trained endoscopy nurse to prepare and handle the necessary instrumentation. In some other cases, well demonstrated in nonvariceal upper gastrointestinal bleeding, early endoscopy facilitates appropriate patient management and disposition (3).

The second key finding pertained to after-hours decontamination practices. It is very concerning to note that, in provinces where endoscopy nurses tend not to be available on-call, endoscopists and/or residents may be directly responsible for endoscope cleaning and reprocessing. The absence of trained specialized staff for endoscope cleaning and decontamination appears to be a direct consequence of the absence of an on-call endoscopy nurse. In essence, this adds 'insult to injury' to this situation - not only are the most critically ill patients not receiving optimal, specialized endoscopy care but endoscope reprocessing under these circumstances may be substandard, putting all endoscopy patients (urgent and routine) at risk.

The survey shows that in many parts of Canada, on-call endoscopy nurses are the accepted standard of care. On-call endoscopy nurses have been available at the three acute care hospitals in Calgary (Alberta) for more than a decade. There are clear benefits for the endoscopist in terms of working with a 'known quantity' when performing some of the most challenging and anxiety-provoking cases. There are clear benefits to the endoscopy units in terms of reduced equipment damage and costs from having the endoscopes cared for by experts. Finally, there are certainly clear benefits to the hospital because endoscopists are likely more willing to perform procedures that may expedite patient care and facilitate early discharge; for example, on patients with upper gastrointestinal hemorrhage.

However, there can be downsides to having ready access to on-call nurses that need to be anticipated. The indication for on-call endoscopy can drift to include less urgent cases to the point in which common referrers, such as emergency rooms, medical teaching units and intensivce care units, come to expect essentially immediate service for all cases. For example, looking back at this past weekend, four to six gastroscopies and three to five colonoscopies were performed at each Calgary hospital. At the hospital that acts as the single site for endoscopic retrograde cholangiopancreatography in Calgary, nursing overtime hours reached the point at which it was more cost effective to have two nurses scheduled for a regular $8 \mathrm{~h}$ shift on Sundays. Frequent call-backs can affect the well-being of nursing staff. The introduction of a regular Sunday nursing shift resulted in a halving of overtime hours, but also a significant decrease in nurses' sick days.

Clearly, resources and funding are issues for all facilities, but from the patients' perspective, it is crucial that their procedures be undertaken by individuals with the necessary skill sets and equipment. Furthermore, the issue of staffing for endoscopic procedures should be addressed more holistically because there appears to be, in some cases, unnecessary staffing for some of the routine cases. For example, nonurgent diagnostic procedures only require the assistance of one endoscopy nurse, likely making the presence of an additional nurse in the room superfluous.

The CAG's Clinical Affairs survey (1) correctly points to a service gap in Canada. Standards should be set, stating that trained endoscopy nurses for after-hours procedures be universally available; that routine diagnostic procedures require the assistance of only one endoscopy nurse; and that endoscope cleaning and reprocessing should exclusively be the responsibility of personnel trained in decontamination.

\section{REFERENCES}

1. Muthiah KC, Enns R, Armstrong D, et al. A survey of the practice of after-hours and emergency endoscopy in Canada. Can J Gastroenterol 2012;26:871-6.

2. Porostocky P, Chiba N, Colacino P, et al. A survey of sedation practices for colonoscopy in Canada. Can J Gastroenterol 2011;25:255-60.

3. Barkun AN, Bardou M, Kuipers EJ, et al. International consensus recommendations on the management of patients with nonvariceal upper gastrointestinal bleeding. Ann Int Med 2010;152:101-13.

Division of Gastroenterology, Department of Medicine, University of Calgary, Calgary, Alberta

Correspondence: Dr Catherine Dubé, Division of Gastroenterology, Department of Medicine, 6th Floor, Teaching, Research and Wellness Building,

University of Calgary, 3280 Hospital Drive Northwest, Calgary, Alberta T2N 4N1. Telephone 403-592-5089, fax 403-592-5090,

e-maildubec@ucalgary.ca

Received and accepted for publication November 7, 2012 


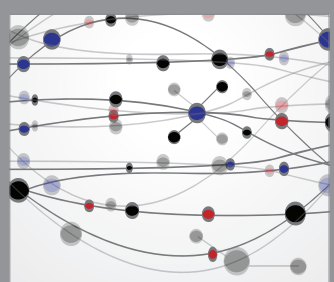

The Scientific World Journal
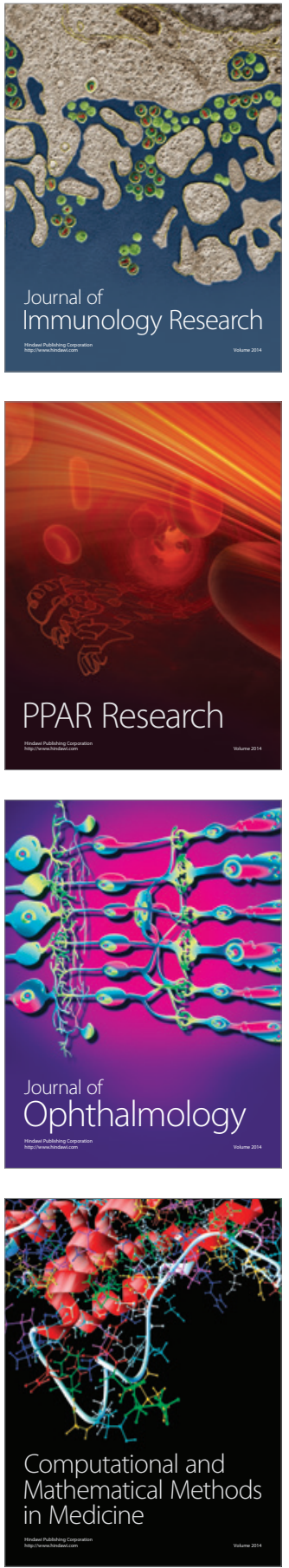

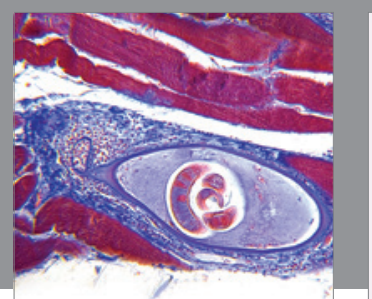

Gastroenterology Research and Practice

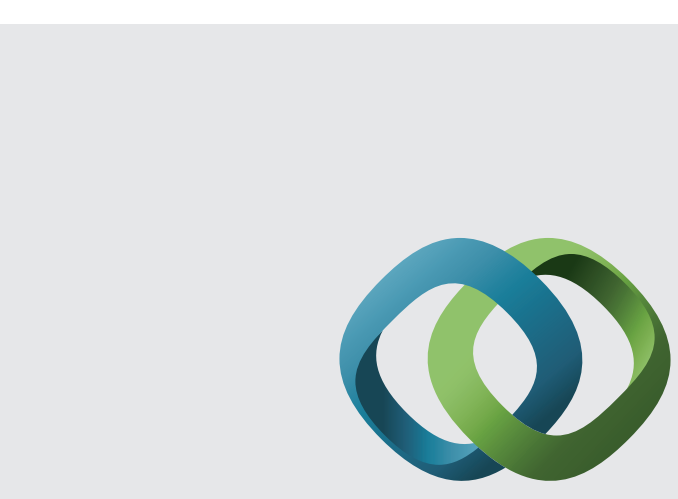

\section{Hindawi}

Submit your manuscripts at

http://www.hindawi.com
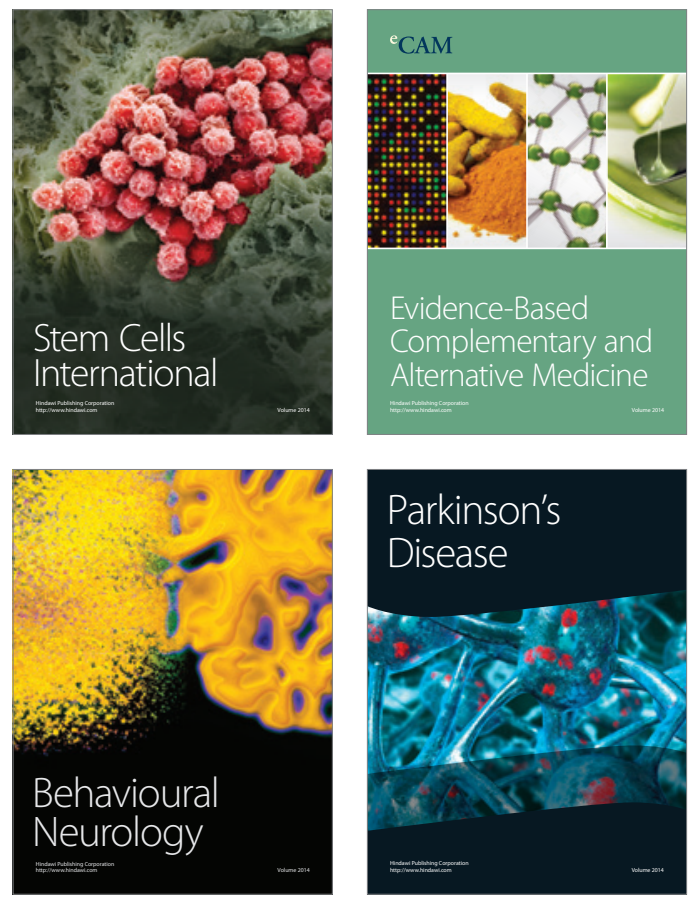
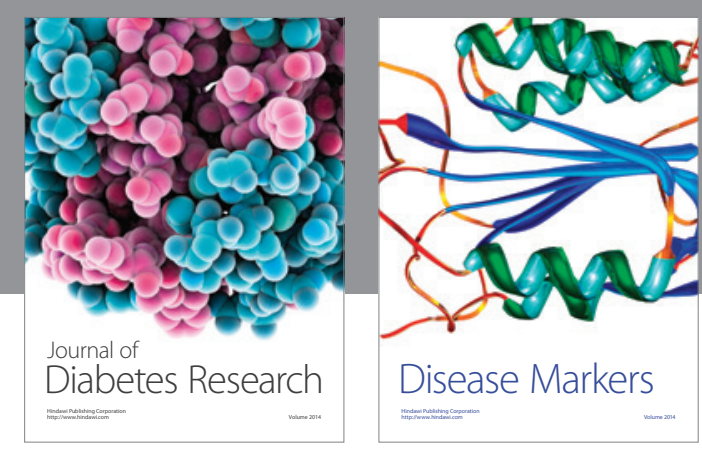

Disease Markers
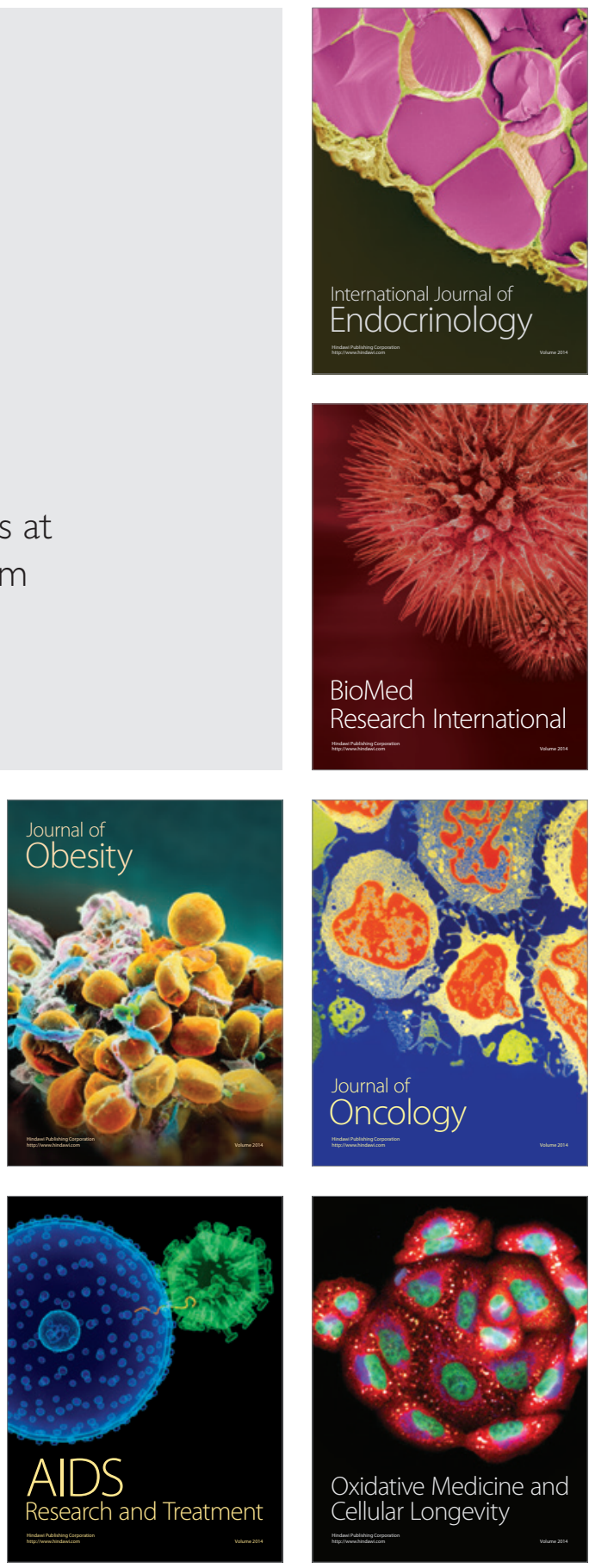